\title{
Proyecciones del urbanismo contemporáneo
}

Arqto. Roberto Humeres Solar (1937)

Filiación: Roberto Humeres Solar fue Arquitecto Urbanista, diplomado en el Instituto de Urbanismo de París, y Jefe de la Sección de Urbanismo de la Municipalidad de Santiago, donde estuvo a cargo de profundizar el Plano Oficial de Urbanización de la Comuna de Santiago entregado por Karl Brunner en 1934, y de llevarlo a cabo desde su aprobación en 1939 y hasta 1957.

\section{Resumen}

Se destaca que la complejidad de los problemas urbanos exige un abordaje multidisciplinario para su resolución. Se observa cómo la evolución política habida en los primeros decenios del siglo XX contribuyó a robustecer los principios en que se funda el Urbanismo, considerando la subordinación del interés particular al interés colectivo. Luego de reseñar las limitaciones del Urbanismo en Chile de su época, Humeres prevé que el Urbanismo tendrá a futuro no sólo una extensión regional o nacional, sino también continental y mundial, en la perspectiva de una solución más coordinada e integral para las necesidades de la humanidad.

Palabras claves: PROYECCIONES DEL URBANISMO; ROBERTO HUMERES SOLAR.

\section{The future of contemporary urbanism}

\begin{abstract}
The complexity of urban problems demands international and interdisciplinary actions. Politics in the first two decades of 20th century developed a strong basis for urbanism. The author foresees an international and global urbanism, in the perspective of coordinated projects.
\end{abstract}

Keywords: CHILEAN URBANISM, INTERNATIONAL URBANISM, POLITICS AND URBANISM. 
Los orígenes del Urbanismo -como los de todas aquellas ciencias que tienen su raigambre en las necesidades fundamentales de la sociedad humana- remontan a las más lejanas civilizaciones. Bástenos recordar la ciudad de Kahun, construída por Sesostris en la vecindad de su pirámide hacia el año 2500 A.J., en cuya planta podemos comprobar las preocupaciones de orden funcional que guiaron su trazado, principalmente en lo que se refiere a la especialización de los barrios, que hoy día [1937] Ilamamos zonificación.

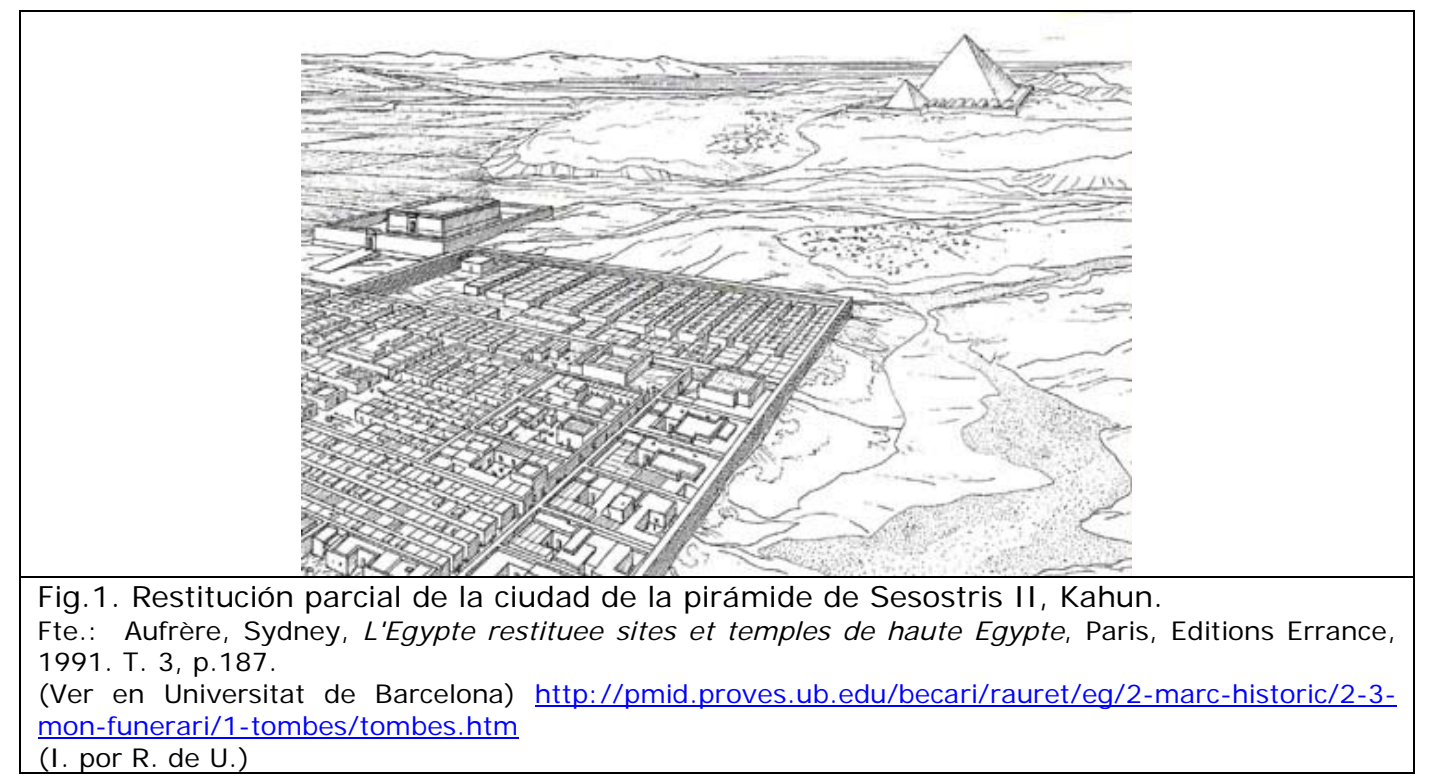

Bastante conocidas son las figuras de Hipódamos de Mileto y de Vitruvio para insistir en el valioso aporte que significaron sus doctrinas para el desarrollo de la ciencia urbanística en la antiguedad clásica. Camilo Sitte nos ha demostrado cómo las admirables creaciones plásticas de la Edad Media - que aun hoy día podemos admirar en Florencia, Chartres, Rotemburgo y tantas otras ciudades europeas- no fueron debidas al azar, sino a una ciencia refinada. No fueron ajenos los más selectos espíritus del Renacimiento a las preocupaciones urbanísticas. Prueba de ello son los curiosos proyectos de "ciudades ideales" que trazaran Leonardo, Durero, Vesari y tantos otros preclaros humanistas.

Pero sólo en el siglo XIX -debido a la complejidad creciente de la vida urbana, engendrada por la formidable eclosión de la gran industria, a causa de los progresos de la mecánica- los Poderes Públicos se ven impelidos a intervenir y, en lo posible, a regular el desarrollo sin precedentes de estas "ciudades tentaculares", que succionan la población agrícola, transformándola en proletariado urbano, en esa formidable clase obrera que dará su verdadera fisonomía a la ciudad contemporánea.

Esta brusca y profunda transformación urbana ha creado nuevos problemas y exigido también métodos nuevos para encararlos. El Urbanismo ha debido echar mano de todos los elementos con que las más variadas ciencias y técnicas modernas podían contribuir para servir sus propósitos.

Es así como esta ciencia ha llegado a coordinar las actividades sociales más diversas, y hoy día los colaboradores más preciosos del urbanista son el abogado, el ingeniero, el economista, el arquitecto, el higienista, el estadístico, el meteorólogo, etc., ya que la finalidad del Urbanismo es hacer funcionar con el mínimum de fricciones los delicados rodajes tanto técnicos como sociales y económicos del vasto y complejo mecanismo urbano. 
La evolución política acaecida en los últimos decenios [primeros decenios del siglo $\mathrm{XX}$ ] ha contribuido a robustecer los principios en que se funda el Urbanismo, dado que las limitaciones del Derecho de Propiedad que acarrea la subordinación del interés particular al interés colectivo -por la serie de servidumbres de todo género que esta necesidad urbanística implica- no podrían acomodarse con el régimen liberal, que se basa en el respeto sagrado de la propiedad privada.

Gracias a las servidumbres legales se ha logrado dividir la ciudad en zonas, según la función que les quepa desempeñar en el concierto urbano. Más aún, se ha conseguido estructurar las regiones que gravitan económicamente en la órbita de un núcleo urbano determinado. Yendo más lejos por esta senda, países cuyos regímenes políticos difieren del que impera en nuestro país [Chile, 1937], han logrado someter la economía nacional a un vasto plan de organización de la producción, de acuerdo con principios funcionales cuyo origen se encuentra en las doctrinas sustentadas por los urbanistas.

En Chile, si aún no estamos preparados para tan vastas empresas, al menos estamos facultados para establecer el comercio a la vera de las arterias de tránsito o en el corazón de la ciudad; las zonas residenciales en barrios escogidos de antemano por su carácter apacible, rozados sólo tangencialmente por las arterias de tránsito, y las industrias en sectores favorables desde el punto de vista de los vientos reinantes, de las vías férreas y de las comunicaciones terrestres, fluviales o marítimas.

Además, podemos limitar el crecimiento innecesario, antihigiénico y costoso de las ciudades, mediante la limitación progresiva de las dimensiones de los predios y la determinación de su destino, la ubicación en la periferia urbana de zonas de espacios libres de reserva entregados transitoriamente al cultivo agrícola y susceptibles de ser transformados en bosques y paseos públicos.

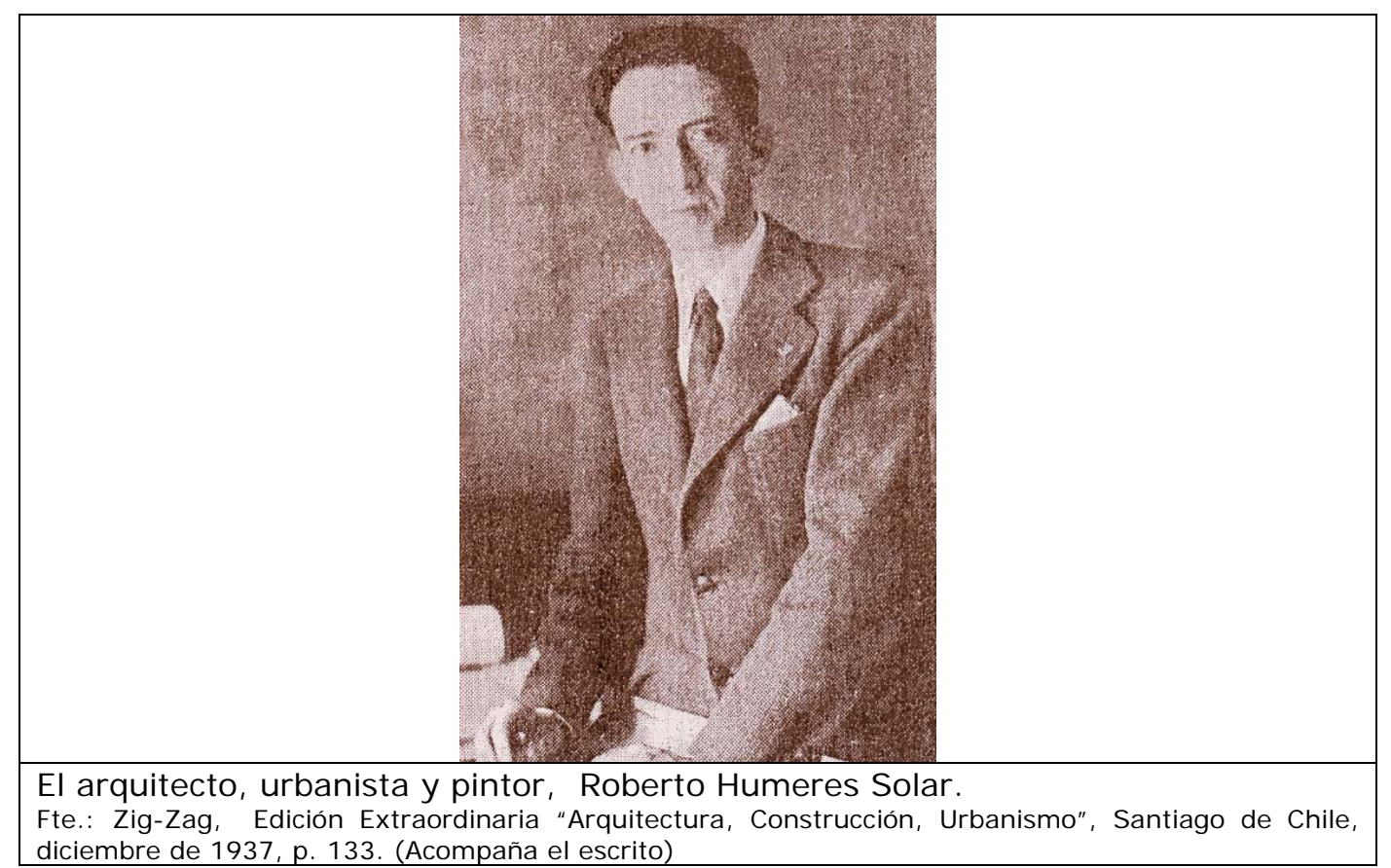

Los instrumentos legales de que disponemos nos permiten asimismo limitar la altura de los edificios a dimensiones económicas e higiénicas suficientes, evitando de este modo la especulación injustificada originada por la sobrevalorización del terreno. Podemos defendernos también de los peligros que engendra el exceso de 
densidad de población, mediante la fijación de coeficientes máximos de aprovechamiento del terreno con fines de edificación, coeficientes que deben guardar estrecha relación con la altura de las construcciones y con las dimensiones mínimas de los predios.

Como se podrá apreciar, las proyecciones de la ciencia del Urbanismo son vastas y su radio de acción se irá ampliando cada día.

Hoy, es un principio universalmente aceptado el que la Política se va adaptando a las necesidades de la Economía, pero con un ritmo lento, que la hace ir siempre a la zaga de esta última.

En nuestra época - gracias al perfeccionamiento de los medios de transporte- se ha producido el fenómeno que hace venir los productos que necesitamos para nuestra subsistencia de los países más diversos y remotos. Ocurre también que en muchos casos los productos importados serían para nosotros más abordables que los de nuestro propio suelo. Sin embargo, mantenemos artificialmente estos artículos alejados de nuestra economía mediante barreras políticas.

De este modo, se produce la paradoja de que ciertos países sufren de hambre mientras otros destruyen las cosechas; industrias similares que producen en cantidad mayor de la que puede absorber el mercado y que se hacen la guerra entre sí, terminando por producir crisis periódicas de superproducción.

Llegará, sin embargo, el día en que la política siga las tendencias internacionales que ha originado la técnica capitalista, y veremos encauzarse por nuevas sendas al Urbanismo, que, dejando de serlo sólo desde el punto de vista urbano, regional o nacional, pasará al plano continental y acaso mundial.

Regularemos los países, como hoy regulamos las regiones que gravitan económicamente alrededor de los núcleos urbanos. Distribuiremos las zonas destinadas a la minería, a la industria, al cultivo agrícola o a la explotación agropecuaria, alrededor de sus centros funcionales. Determinaremos los coeficientes y las cifras máximas de producción, de acuerdo con las necesidades efectivas del consumo internacional. Acabaremos de este modo con la especulación y con los abusos del capitalismo.

Pero si todo esto es muy hermoso y aún posible, no serán seguramente los hombres de nuestra generación quienes vean realizada esta magnífica aspiración de la humanidad. 